\title{
Almost contractive coupled mapping in ordered complete metric spaces
}

\author{
Wasfi Shatanawi ${ }^{1}$, Reza Saadati ${ }^{2}$ and Choonkil Park ${ }^{3 *}$
}

"Correspondence:

baak@hanyang.ac.kr

${ }^{3}$ Department of Mathematics,

Research Institute for Natural

Sciences, Hanyang University, Seoul,

133-791, Korea

Full list of author information is

available at the end of the article

\begin{abstract}
In this paper, we introduce the notion of almost contractive mapping $F: X \times X \rightarrow X$ with respect to the mapping $g: X \rightarrow X$ and establish some existence and uniqueness theorems of a coupled common coincidence point in ordered complete metric spaces. Also, we introduce an example to support our main results. Our results generalize several well-known comparable results in the literature.
\end{abstract}

MSC: $54 \mathrm{H} 25 ; 47 \mathrm{H} 10 ; 34 \mathrm{~B} 15$

Keywords: coupled fixed point; partially ordered set; mixed monotone property

\section{Introduction and preliminaries}

The existence and uniqueness theorems of a fixed point in complete metric spaces play an important role in constructing methods for solving problems in differential equations, matrix equations, and integral equations. Furthermore, the fixed point theory is a crucial method in numerical analysis to present a way for solving and approximating the roots of many equations in real analysis. One of the main theorems on a fixed point is the Banach contraction theorem [1]. Many authors generalized the Banach contraction theorem in different metric spaces in different ways. For some works on fixed point theory, we refer the readers to [2-17]. The study of a coupled fixed point was initiated by Bhaskar and Lakshmikantham [18]. Bhaskar and Lakshmikantham [18] obtained some nice results on a coupled fixed point and applied their results to solve a pair of differential equations. For some results on a coupled fixed point in ordered metric spaces, we refer the reader to [18-26].

The following definitions will be needed in the sequel.

Definition 1.1 Let $(X, \preceq)$ be a partially ordered set and $F: X \times X \rightarrow X$. The mapping $F$ is said to have the mixed monotone property if $F(x, y)$ is monotone non-decreasing in $x$ and is monotone non-increasing in $y$, that is, for any

$$
x, y \in X, x_{1}, x_{2} \in X, \quad x_{1} \preceq x_{2} \quad \Rightarrow \quad F\left(x_{1}, y\right) \preceq F\left(x_{2}, y\right)
$$

and

$$
y_{1}, y_{2} \in X, \quad y_{1} \preceq y_{2} \quad \Rightarrow \quad F\left(x, y_{1}\right) \succeq F\left(x, y_{2}\right)
$$

@2013 Shatanawi et al.; licensee Springer. This is an Open Access article distributed under the terms of the Creative Commons Attribution License (http://creativecommons.org/licenses/by/2.0), which permits unrestricted use, distribution, and reproduction in any medium, provided the original work is properly cited. 
Definition 1.2 We call an element $(x, y) \in X \times X$ a coupled fixed point of the mapping $F: X \times X \rightarrow X$ if

$$
F(x, y)=x \quad \text { and } \quad F(y, x)=y .
$$

Definition 1.3 [20] Let $(X, \preceq)$ be a partially ordered set and $F: X \times X \rightarrow X$ and $g: X \rightarrow X$. The mapping $F$ is said to have the mixed $g$-monotone property if $F$ is monotone $g$-nondecreasing in its first argument and is monotone $g$-non-increasing in its second argument, that is, for any $x, y \in X$,

$$
x_{1}, x_{2} \in X, \quad g\left(x_{1}\right) \preceq g\left(x_{2}\right) \quad \Rightarrow \quad F\left(x_{1}, y\right) \preceq F\left(x_{2}, y\right)
$$

and

$$
y_{1}, y_{2} \in X, \quad g\left(y_{1}\right) \preceq g\left(y_{2}\right) \quad \Rightarrow \quad F\left(x, y_{1}\right) \succeq F\left(x, y_{2}\right) .
$$

Definition 1.4 An element $(x, y) \in X \times X$ is called a coupled coincidence point of the mappings $F: X \times X \rightarrow X$ and $g: X \rightarrow X$ if

$$
F(x, y)=g(x) \quad \text { and } \quad F(y, x)=g(y) .
$$

The main results of Bhaskar and Lakshmikantham in [18] are the following.

Theorem 1.1 [18] Let $(X, \preceq)$ be a partially ordered set and $d$ be a metric on $X$ such that $(X, d)$ is a complete metric space. Let $F: X \times X \rightarrow X$ be a continuous mapping having the mixed monotone property on $X$. Assume that there exists a $k \in[0,1)$ with

$$
d(F(x, y), F(u, v)) \leq \frac{k}{2}[d(x, u)+d(y, v)] \quad \forall x \succeq u \text { and } y \preceq v .
$$

If there exist two elements $x_{0}, y_{0} \in X$ with

$$
x_{0} \preceq F\left(x_{0}, y_{0}\right) \text { and } y_{0} \succeq F\left(y_{0}, x_{0}\right) \text {, }
$$

then there exist $x, y \in X$ such that

$$
x=F(x, y) \text { and } y=F(y, x) .
$$

Theorem $1.2[18]$ Let $(X, \preceq)$ be a partially ordered set and $d$ be a metric on $X$ such that $(X, d)$ is a complete metric space. Assume that $X$ has the following property:

(i) if a nondecreasing sequence $\left\{x_{n}\right\}$ in $X$ converges to $x \in X$, then $x_{n} \preceq x$ for all $n$,

(ii) if a nonincreasing sequence $\left\{y_{n}\right\}$ in $X$ converges to $y \in X$, then $y_{n} \succeq y$ for all $n$.

Let $F: X \times X \rightarrow X$ be a mapping having the mixed monotone property on $X$. Assume that there exists $k \in[0,1)$ with

$$
d(F(x, y), F(u, v)) \leq \frac{k}{2}[d(x, u)+d(y, v)] \quad \forall x \succeq u \text { and } y \preceq v .
$$


If there exist two elements $x_{0}, y_{0} \in X$ with

$$
x_{0} \preceq F\left(x_{0}, y_{0}\right) \quad \text { and } \quad y_{0} \succeq F\left(y_{0}, x_{0}\right) \text {, }
$$

then there exist $x, y \in X$ such that

$$
x=F(x, y) \text { and } y=F(y, x) .
$$

Definition 1.5 Let $(X, d)$ be a metric space and $F: X \times X \rightarrow X$ and $g: X \rightarrow X$ be mappings. We say that $F$ and $g$ commute if

$$
F(g(x), g(y))=g(F(x, y))
$$

for all $x, y \in X$.

Nashine and Shatanawi [22] proved the following coupled coincidence point theorems.

Theorem 1.3 [22] Let $(X, d, \preceq)$ be an ordered metric space. Let $F: X \times X \rightarrow X$ and $g: X \rightarrow X$ be mappings such that $F$ has the mixed $g$-monotone property on $X$ such that there exist two elements $x_{0}, y_{0} \in X$ with $g\left(x_{0}\right) \preceq F\left(x_{0}, y_{0}\right)$ and $g\left(y_{0}\right) \succeq F\left(y_{0}, x_{0}\right)$. Suppose that there exist non-negative real numbers $\alpha, \beta, L$ with $\alpha+\beta<1$ such that

$$
\begin{aligned}
d(F(x, y), F(u, v)) \leq & \alpha \min \{d(F(x, y), g(x)), d(F(u, v), g(x))\} \\
& +\beta \min \{d(F(x, y), g(u)), d(F(u, v), g(u))\} \\
& +L \min \{d(F(x, y), g(u)), d(F(u, v), g(x))\}
\end{aligned}
$$

for all $(x, y),(u, v) \in X \times X$ with $g(x) \preceq g(u)$ and $g(y) \succeq g(v)$. Further suppose that $F(X \times$ $X) \subseteq g(X)$ and $g(X)$ is a complete subspace of $X$. Also suppose that $X$ satisfies the following properties:

(i) if a nondecreasing sequence $\left\{x_{n}\right\}$ in $X$ converges to $x \in X$, then $x_{n} \preceq x$ for all $n$,

(ii) if a nonincreasing sequence $\left\{y_{n}\right\}$ in $X$ converges to $y \in X$, then $y_{n} \geq y$ for all $n$.

Then there exist $x, y \in X$ such that

$$
F(x, y)=g(x) \quad \text { and } \quad F(y, x)=g(y)
$$

that is, $F$ and $g$ have a coupled coincidence point $(x, y) \in X \times X$.

Theorem 1.4 [22] Let $(X, \preceq)$ be a partially ordered set and suppose that there is a metric $d$ on $X$ such that $(X, d)$ is a complete metric space. Let $F: X \times X \rightarrow X$ and $g: X \rightarrow X$ be mappings such that $F$ has the mixed $g$-monotone property on $X$ such that there exist two elements $x_{0}, y_{0} \in X$ with $g\left(x_{0}\right) \preceq F\left(x_{0}, y_{0}\right)$ and $g\left(y_{0}\right) \succeq F\left(y_{0}, x_{0}\right)$. Suppose that there exist non-negative real numbers $\alpha, \beta, L$ with $\alpha+\beta<1$ such that

$$
\begin{aligned}
d(F(x, y), F(u, v)) \leq & \alpha \min \{d(F(x, y), g(x)), d(F(u, v), g(x))\} \\
& +\beta \min \{d(F(x, y), g(u)), d(F(u, v), g(u))\} \\
& +L \min \{d(F(x, y), g(u)), d(F(u, v), g(x))\}
\end{aligned}
$$


for all $(x, y),(u, v) \in X \times X$ with $g(x) \preceq g(u)$ and $g(y) \succeq g(v)$. Further suppose that $F(X \times X) \subseteq$ $g(X), g$ is continuous nondecreasing and commutes with $F$, and also suppose that either

(a) $F$ is continuous, or

(b) $X$ has the following property:

(i) if a nondecreasing sequence $\left\{x_{n}\right\}$ in $X$ converges to $x \in X$, then $x_{n} \preceq x$ for all $n$,

(ii) if a nonincreasing sequence $\left\{y_{n}\right\}$ in $X$ converges to $y \in X$, then $y_{n} \succeq y$ for all $n$.

Then there exist $x, y \in X$ such that

$$
F(x, y)=g(x) \quad \text { and } \quad F(y, x)=g(y)
$$

that is, $F$ and $g$ have a coupled coincidence point $(x, y) \in X \times X$.

Berinde [27-30] initiated the concept of almost contractions and studied many interesting fixed point theorems for a Ćirić strong almost contraction. So, it is fundamental to recall the following definition.

Definition 1.6 [27] A single-valued mapping $f: X \times X$ is called a Ćirić strong almost contraction if there exist a constant $\alpha \in[0,1)$ and some $L \geq 0$ such that

$$
d(f x, f y) \leq \alpha M(x, y)+L d(y, f x)
$$

for all $x, y \in X$, where

$$
M(x, y)=\max \left\{d(x, y), d(x, f x), d(y, f y), \frac{d(x, f y)+d(y, f x)}{2}\right\} .
$$

The aim of this paper is to introduce the notion of almost contractive mapping $F: X \times$ $X \rightarrow X$ with respect to the mapping $g: X \rightarrow X$ and present some uniqueness and existence theorems of coupled fixed and coincidence point. Our results generalize Theorems 1.1-1.4.

\section{Main theorems}

We start with the following definition.

Definition 2.1 Let $(X, d, \preceq)$ be an ordered metric space. We say that the mapping $F: X \times$ $X \rightarrow X$ is an almost contractive mapping with respect to the mapping $g: X \rightarrow X$ if there exist a real number $\alpha \in[0,1)$ and a nonnegative number $L$ such that

$$
\begin{aligned}
& d(F(x, y), F(u, v)) \\
& \quad \leq \alpha \max \{d(g(x), g(u)), d(g(y), g(v)), d(F(x, y), g(x)), d(F(u, v), g(u))\} \\
& \quad+L \min \{d(F(x, y), g(u)), d(F(u, v), g(x))\}
\end{aligned}
$$

for all $(x, y),(u, v) \in X \times X$ with $g(x) \preceq g(u)$ and $g(y) \succeq g(v)$.

Theorem 2.1 Let $(X, d, \preceq)$ be an ordered metric space. Let $F: X \times X \rightarrow X$ and $g: X \rightarrow X$ be mappings such that

(1) $F$ is an almost contractive mapping with respect to $g$. 
(2) F has the mixed g-monotone property on $X$.

(3) There exist two elements $x_{0}, y_{0} \in X$ with $g\left(x_{0}\right) \preceq F\left(x_{0}, y_{0}\right)$ and $g\left(y_{0}\right) \succeq F\left(y_{0}, x_{0}\right)$.

(4) $F(X \times X) \subseteq g(X)$ and $g(X)$ is a complete subspace of $X$.

Also, suppose that $X$ satisfies the following properties:

(i) if a nondecreasing sequence $\left\{x_{n}\right\}$ in $X$ converges to $x \in X$, then $x_{n} \preceq x$ for all $n$,

(ii) if a nonincreasing sequence $\left\{y_{n}\right\}$ in $X$ converges to $y \in X$, then $y_{n} \succeq y$ for all $n$.

Then there exist $x, y \in X$ such that

$$
F(x, y)=g(x) \text { and } F(y, x)=g(y)
$$

that is, $F$ and $g$ have a coupled coincidence point $(x, y) \in X \times X$.

Proof Let $x_{0}, y_{0} \in X$ be such that $g\left(x_{0}\right) \preceq F\left(x_{0}, y_{0}\right)$ and $g\left(y_{0}\right) \succeq F\left(y_{0}, x_{0}\right)$. Since $F(X \times X) \subseteq$ $g(X)$, we can choose $x_{1}, y_{1} \in X$ such that $g\left(x_{1}\right)=F\left(x_{0}, y_{0}\right)$ and $g\left(y_{1}\right)=F\left(y_{0}, x_{0}\right)$.

In the same way, we construct $g\left(x_{2}\right)=F\left(x_{1}, y_{1}\right)$ and $g\left(y_{2}\right)=F\left(y_{1}, x_{1}\right)$.

Continuing in this way, we construct two sequences $\left\{x_{n}\right\}$ and $\left\{y_{n}\right\}$ in $X$ such that

$$
g\left(x_{n+1}\right)=F\left(x_{n}, y_{n}\right) \quad \text { and } \quad g\left(y_{n+1}\right)=F\left(y_{n}, x_{n}\right) \quad \forall n \in \mathbb{N} \cup\{0\}
$$

Since $F$ has the mixed $g$-monotone property, by induction we may show that

$$
g\left(x_{0}\right) \preceq g\left(x_{1}\right) \preceq g\left(x_{2}\right) \preceq \cdots \preceq g\left(x_{n+1}\right) \preceq \cdots
$$

and

$$
g\left(y_{0}\right) \succeq g\left(y_{1}\right) \succeq g\left(y_{2}\right) \succeq \cdots \succeq g\left(y_{n+1}\right) \succeq \cdots .
$$

If $\left(g\left(x_{n+1}\right), g\left(y_{n+1}\right)\right)=\left(g\left(x_{n}\right), g\left(y_{n}\right)\right)$ for some $n \in \mathbb{N}$, then $F\left(x_{n}, y_{n}\right)=g\left(x_{n}\right)$ and $F\left(y_{n}, x_{n}\right)=$ $g\left(y_{n}\right)$, that is, $\left(x_{n}, y_{n}\right)$ is a coincidence point of $F$ and $g$. So we may assume that $\left(g\left(x_{n+1}\right)\right.$, $\left.g\left(y_{n+1}\right)\right) \neq\left(g\left(x_{n}\right), g\left(y_{n}\right)\right)$ for all $n \in \mathbb{N}$. Let $n \in \mathbb{N}$. Since $g\left(x_{n}\right) \succeq g\left(x_{n-1}\right)$ and $g\left(y_{n}\right) \preceq g\left(y_{n-1}\right)$, from (5) and (6), we have

$$
\begin{aligned}
d( & \left.g\left(x_{n}\right), g\left(x_{n+1}\right)\right) \\
= & d\left(F\left(x_{n-1}, y_{n-1}\right), F\left(x_{n}, y_{n}\right)\right) \\
\leq & \alpha \max \left\{d\left(g\left(x_{n-1}\right), g\left(x_{n}\right)\right), d\left(g\left(y_{n-1}\right), g\left(y_{n}\right)\right), d\left(F\left(x_{n}, y_{n}\right), g\left(x_{n}\right)\right),\right. \\
& \left.d\left(F\left(x_{n-1}, y_{n-1}\right), g\left(x_{n-1}\right)\right)\right\}+L \min \left\{d\left(F\left(x_{n}, y_{n}\right), g\left(x_{n-1}\right)\right), d\left(F\left(x_{n-1}, y_{n-1}\right), g\left(x_{n}\right)\right)\right\} \\
= & \alpha \max \left\{d\left(g\left(x_{n-1}\right), g\left(x_{n}\right)\right), d\left(g\left(y_{n-1}\right), g\left(y_{n}\right)\right), d\left(g\left(x_{n+1}\right), g\left(x_{n}\right)\right), d\left(g\left(x_{n}\right), g\left(x_{n-1}\right)\right)\right\} \\
& +L \min \left\{d\left(g\left(x_{n+1}\right), g\left(x_{n-1}\right)\right), d\left(g\left(x_{n}\right), g\left(x_{n}\right)\right)\right\} \\
= & \alpha \max \left\{d\left(g\left(x_{n-1}\right), g\left(x_{n}\right)\right), d\left(g\left(y_{n-1}\right), g\left(y_{n}\right)\right), d\left(g\left(x_{n+1}\right), g\left(x_{n}\right)\right)\right\} .
\end{aligned}
$$

If $\max \left\{d\left(g\left(x_{n-1}\right), g\left(x_{n}\right)\right), d\left(g\left(y_{n-1}\right), g\left(y_{n}\right)\right), d\left(g\left(x_{n+1}\right), g\left(x_{n}\right)\right)\right\}=d\left(g\left(x_{n+1}\right), g\left(x_{n}\right)\right)$, then $d\left(g\left(x_{n+1}\right)\right.$, $\left.g\left(x_{n}\right)\right) \leq \alpha d\left(g\left(x_{n+1}\right), g\left(x_{n}\right)\right)$ and hence $d\left(g\left(x_{n+1}\right), g\left(x_{n}\right)\right)=0$. Thus $d\left(g\left(x_{n-1}\right), g\left(x_{n}\right)\right)=$ 
$d\left(g\left(y_{n-1}\right), g\left(y_{n}\right)\right)=0$. Therefore $d\left(g\left(x_{n-1}\right), g\left(y_{n-1}\right)\right)=d\left(g\left(x_{n}\right), g\left(y_{n}\right)\right)$, a contradiction. Thus

$$
\begin{aligned}
& \max \left\{d\left(g\left(x_{n-1}\right), g\left(x_{n}\right)\right), d\left(g\left(y_{n-1}\right), g\left(y_{n}\right)\right), d\left(g\left(x_{n+1}\right), g\left(x_{n}\right)\right)\right\} \\
& \quad=\max \left\{d\left(g\left(x_{n-1}\right), g\left(x_{n}\right)\right), d\left(g\left(y_{n-1}\right), g\left(y_{n}\right)\right)\right\} .
\end{aligned}
$$

Therefore

$$
d\left(g\left(x_{n+1}\right), g\left(x_{n}\right)\right) \leq \alpha \max \left\{d\left(g\left(x_{n-1}\right), g\left(x_{n}\right)\right), d\left(g\left(y_{n-1}\right), g\left(y_{n}\right)\right)\right\} .
$$

Similarly, we may show that

$$
d\left(g\left(y_{n}\right), g\left(y_{n+1}\right)\right) \leq \alpha \max \left\{d\left(g\left(x_{n-1}\right), g\left(x_{n}\right)\right), d\left(g\left(y_{n-1}\right), g\left(y_{n}\right)\right)\right\} .
$$

From (7) and (8), we have

$$
\begin{aligned}
& \max \left\{d\left(g\left(x_{n+1}\right), g\left(x_{n}\right)\right), d\left(g\left(y_{n}\right), g\left(y_{n+1}\right)\right)\right\} \\
& \quad \leq \alpha \max \left\{d\left(g\left(x_{n-1}\right), g\left(x_{n}\right)\right), d\left(g\left(y_{n-1}\right), g\left(y_{n}\right)\right)\right\} .
\end{aligned}
$$

Repeating (9) $n$-times, we get

$$
\begin{aligned}
& \max \left\{d\left(g\left(x_{n+1}\right), g\left(x_{n}\right)\right), d\left(g\left(y_{n}\right), g\left(y_{n+1}\right)\right)\right\} \\
& \leq \alpha^{n} \max \left\{d\left(g\left(x_{0}\right), g\left(x_{1}\right)\right), d\left(g\left(y_{0}\right), g\left(y_{1}\right)\right)\right\} .
\end{aligned}
$$

Now, we shall prove that $\left\{g\left(x_{n}\right)\right\}$ and $\left\{g\left(y_{n}\right)\right\}$ are Cauchy sequences in $g(X)$.

For each $m \geq n$, we have

$$
\begin{aligned}
& d\left(g\left(x_{m}\right), g\left(x_{n}\right)\right) \\
& \leq d\left(g\left(x_{n}\right), g\left(x_{n+1}\right)\right)+d\left(g\left(x_{n+1}\right), g\left(x_{n+2}\right)\right)+\cdots \\
& \quad+d\left(g\left(x_{m-1}\right), g\left(x_{m}\right)\right) \\
& \leq \alpha^{n} \max \left\{d\left(g\left(x_{0}\right), g\left(x_{1}\right)\right), d\left(g\left(y_{0}\right), g\left(y_{1}\right)\right)\right\}+\cdots \\
& \quad+\alpha^{m-1} \max \left\{d\left(g\left(x_{0}\right), g\left(x_{1}\right)\right), d\left(g\left(y_{0}\right), g\left(y_{1}\right)\right)\right\} \\
& \leq \frac{\alpha^{n}}{1-\alpha} \max \left\{d\left(g\left(x_{0}\right), g\left(x_{1}\right)\right), d\left(g\left(y_{0}\right), g\left(y_{1}\right)\right)\right\} .
\end{aligned}
$$

Letting $n, m \rightarrow+\infty$ in the above inequalities, we get that $\left\{g\left(x_{n}\right)\right\}$ is a Cauchy sequence in $g(X)$. Similarly, we may show that $\left\{g\left(y_{n}\right)\right\}$ is a Cauchy sequence in $g(X)$. Since $g(X)$ is a complete subspace of $X$, there exists $(x, y) \in X \times X$ such that $g\left(x_{n}\right) \rightarrow g(x)$ and $g\left(y_{n}\right) \rightarrow$ $g(y)$. Since $\left\{g\left(x_{n}\right)\right\}$ is a non-decreasing sequence and $g\left(x_{n}\right) \rightarrow g(x)$ and as $\left\{g\left(y_{n}\right)\right\}$ is a nonincreasing sequence and $g\left(y_{n}\right) \rightarrow g(y)$, by the assumption we have $g\left(x_{n}\right) \preceq g(x)$ and $g\left(y_{n}\right) \succeq$ $g(y)$ for all $n$. Since

$$
\begin{aligned}
& d\left(g\left(x_{n+1}\right), F(x, y)\right) \\
& \quad=d\left(F\left(x_{n}, y_{n}\right), F(x, y)\right)
\end{aligned}
$$




$$
\begin{aligned}
\leq & \alpha \max \left\{d\left(g\left(x_{n}\right), g(x)\right), d\left(g\left(y_{n}\right), g(y)\right), d\left(g\left(x_{n+1}\right), g\left(x_{n}\right)\right), d(F(x, y), g(x))\right\} \\
& +L \min \left\{d\left(g\left(x_{n+1}\right), g(x)\right), d\left(F(x, y), g\left(x_{n}\right)\right)\right\} .
\end{aligned}
$$

Letting $n \rightarrow \infty$ in the above inequality, we get $d(g(x), F(x, y))=0$. Hence $g(x)=F(x, y)$. Similarly, one can show that $g(y)=F(y, x)$. Thus we proved that $F$ and $g$ have a coupled coincidence point.

Theorem 2.2 Let $(X, \preceq)$ be a partially ordered set and suppose that there is a metric d on $X$ such that $(X, d)$ is a complete metric space. Let $F: X \times X \rightarrow X$ and $g: X \rightarrow X$ be mappings such that

(1) $F$ is an almost contractive mapping with respect to $g$.

(2) $F$ has the mixed $g$-monotone property on $X$.

(3) There exist two elements $x_{0}, y_{0} \in X$ with $g\left(x_{0}\right) \preceq F\left(x_{0}, y_{0}\right)$ and $g\left(y_{0}\right) \succeq F\left(y_{0}, x_{0}\right)$.

(4) $F(X \times X) \subseteq g(X)$.

(5) $g$ is continuous nondecreasing and commutes with $F$.

Also suppose that either

(a) $F$ is continuous, or

(b) $X$ has the following property:

(i) if a nondecreasing sequence $\left\{x_{n}\right\}$ in $X$ converges to $x \in X$, then $x_{n} \preceq x$ for all $n$,

(ii) if a nonincreasing sequence $\left\{y_{n}\right\}$ in $X$ converges to $y \in X$, then $y_{n} \succeq y$ for all $n$.

Then there exist $x, y \in X$ such that

$$
F(x, y)=g(x) \quad \text { and } \quad F(y, x)=g(y)
$$

that is, $F$ and $g$ have a coupled coincidence point $(x, y) \in X \times X$.

Proof As in the proof of Theorem 2.1, we construct two Cauchy sequences $\left(g x_{n}\right)$ and $\left(g y_{n}\right)$ in $X$ such that $\left(g x_{n}\right)$ is a nondecreasing sequence in $X$ and $\left(g y_{n}\right)$ is a nonincreasing sequence in $X$. Since $X$ is a complete metric space, there is $(x, y) \in X \times X$ such that $g x_{n} \rightarrow x$ and $g y_{n} \rightarrow y$. Since $g$ is continuous, we have $g\left(g x_{n}\right) \rightarrow g x$ and $g\left(g y_{n}\right) \rightarrow g y$.

Suppose that (a) holds. Since $F$ is continuous, we have $F\left(g x_{n}, g y_{n}\right) \rightarrow F(x, y)$ and $F\left(g y_{n}, g x_{n}\right) \rightarrow F(y, x)$. Also, since $g$ commutes with $F$ and $g$ is continuous, we have $F\left(g x_{n}, g y_{n}\right)=g F\left(x_{n}, y_{n}\right)=g\left(g x_{n+1}\right) \rightarrow g x$ and $F\left(g y_{n}, g x_{n}\right)=g F\left(y_{n}, x_{n}\right)=g\left(g y_{n+1}\right) \rightarrow g y$. By uniqueness of limit, we get $g x=F(x, y)$ and $g y=F(y, x)$.

Second, suppose that (b) holds. Since $g\left(x_{n}\right)$ is a nondecreasing sequence such that $g\left(x_{n}\right) \rightarrow x, g\left(y_{n}\right)$ is a nonincreasing sequence such that $g\left(y_{n}\right) \rightarrow y$, and $g$ is a nondecreasing function, we get that $g\left(g x_{n}\right) \preceq g x$ and $g\left(g y_{n}\right) \succeq g(y)$ hold for all $n \in \mathbb{N}$. By (5), we have

$$
\begin{aligned}
& d(\left(g\left(g x_{n+1}\right), F(x, y)\right) \\
&= d\left(F\left(g x_{n}, g y_{n}\right), F(x, y)\right) \\
& \leq \alpha \max \left\{d\left(g\left(g x_{n}\right), g(x)\right), d\left(g\left(g y_{n}\right), g(y)\right), d\left(g\left(g x_{n+1}\right), g\left(g x_{n}\right)\right), d(F(x, y), g(x))\right\} \\
& \quad+L \min \left\{d\left(g\left(g x_{n+1}\right), g(x)\right), d\left(F(x, y), g\left(g x_{n}\right)\right)\right\} .
\end{aligned}
$$

Letting $n \rightarrow+\infty$, we get $d(g(x), F(x, y))=0$ and hence $g(x)=F(x, y)$. Similarly, one can show that $g(y)=F(y, x)$. Thus $(x, y)$ is a coupled coincidence point of $F$ and $g$. 
Corollary 2.1 Let $(X, \preceq)$ be a partially ordered set and suppose that there is a metric $d$ on $X$ such that $(X, d)$ is a complete metric space. Let $F: X \times X \rightarrow X$ be a mapping such that $F$ has the mixed monotone property on $X$ such that there exist two elements $x_{0}, y_{0} \in X$ with $x_{0} \preceq F\left(x_{0}, y_{0}\right)$ and $y_{0} \succeq F\left(y_{0}, x_{0}\right)$. Suppose that there exist a real number $\alpha \in[0,1)$ and $a$ nonnegative number $L$ such that

$$
\begin{aligned}
d(F(x, y), F(u, v)) \leq & \alpha \max \{d(x, u), d(y, v), d(F(x, y), x), d(F(u, v), u)\} \\
& +L \min \{d(F(x, y), u), d(F(u, v), x)\}
\end{aligned}
$$

for all $(x, y),(u, v) \in X \times X$ with $x \preceq u$ and $y \succeq v$ and also suppose that either

(a) $F$ is continuous, or

(b) $X$ has the following property:

(i) if a nondecreasing sequence $\left\{x_{n}\right\}$ in $X$ converges to $x \in X$, then $x_{n} \preceq x$ for all $n$,

(ii) if a nonincreasing sequence $\left\{y_{n}\right\}$ in $X$ converges to $y \in X$, then $y_{n} \succeq y$ for all $n$,

then there exist $x, y \in X$ such that

$$
F(x, y)=x \quad \text { and } \quad F(y, x)=y \text {, }
$$

that is, $F$ has a coupled fixed point $(x, y) \in X \times X$.

Proof Follows from Theorem 2.2 by taking $g=I$, the identity mapping.

Let $(X, \preceq)$ be a partially ordered set. Then we define a partial order $\preceq$ on the product space $X \times X$ as follows:

$$
\text { for }(x, y),(u, v) \in X \times X, \quad(u, v) \preceq(x, y) \quad \Leftrightarrow \quad x \succeq u, \quad y \preceq v .
$$

Now, we prove some uniqueness theorem of a coupled common fixed point of mappings $F: X \times X \rightarrow X$ and $g: X \rightarrow X$.

Theorem 2.3 In addition to the hypotheses of Theorem 2.1, suppose that $L=0, \alpha<\frac{1}{2}, F$ and $g$ commute and for every $(x, y),\left(y^{*}, x^{*}\right) \in X \times X$, there exists $(u, v) \in X \times X$ such that $(F(u, v), F(v, u))$ is comparable to $(F(x, y), F(y, x))$ and $\left(F\left(x^{*}, y^{*}\right), F\left(y^{*}, x^{*}\right)\right)$. Then $F$ and $g$ have a unique coupled common fixed point, that is, there exists a unique $(x, y) \in X \times X$ such that

$$
x=g(x)=F(x, y) \text { and } \quad y=g(y)=F(y, x) .
$$

Proof The existence of coupled coincidence points of $F$ and $g$ follows from Theorem 2.1. To prove the uniqueness, let $(x, y)$ and $\left(x^{*}, y^{*}\right)$ be coupled coincidence points of $F$ and $g$; that is, $g(x)=F(x, y), g(y)=F(y, x), g\left(x^{*}\right)=F\left(x^{*}, y^{*}\right)$ and $g\left(y^{*}\right)=F\left(y^{*}, x^{*}\right)$. Now, we prove that

$$
g(x)=g\left(x^{*}\right) \text { and } g(y)=g\left(y^{*}\right) .
$$

By the hypotheses, there exists $(u, v) \in X \times X$ such that $(F(u, v), F(v, u))$ is comparable to $(F(x, y), F(y, x))$ and $\left(F\left(x^{*}, y^{*}\right), F\left(y^{*}, x^{*}\right)\right)$. Put $u_{0}=u, v_{0}=v$. Let $u_{1}, v_{1} \in X$ be such that 
$g\left(u_{1}\right)=F\left(u_{0}, v_{0}\right)$ and $g\left(v_{1}\right)=F\left(v_{0}, u_{0}\right)$. Then as a similar proof of Theorem 2.1, we construct two sequences $\left\{g\left(u_{n}\right)\right\},\left\{g\left(v_{n}\right)\right\}$ in $g(X)$, where $g\left(u_{n+1}\right)=F\left(u_{n}, v_{n}\right)$ and $g\left(v_{n+1}\right)=F\left(v_{n}, u_{n}\right)$ for all $n \in \mathbb{N}$. Further, set $x_{0}=x, y_{0}=y, x_{0}^{*}=x^{*}, y_{0}^{*}=y^{*}$. Define the sequences $\left\{g\left(x_{n}\right)\right\}$, $\left\{g\left(y_{n}\right)\right\}$ in the following way: define $g x_{1}=F\left(x_{0}, y_{0}\right)=F(x, y)$ and $g y_{1}=F\left(y_{0}, x_{0}\right)=F(y, x)$. Also, define $g x_{2}=F\left(x_{1}, y_{1}\right)$ and $g y_{2}=F\left(y_{1}, x_{1}\right)$. For each $n \in \mathbb{N}$, define $g x_{n+1}=F\left(x_{n}, y_{n}\right)$ and $g y_{n+1}=F\left(y_{n}, x_{n}\right)$. In the same way, we define the sequences $\left\{g\left(x_{n}^{*}\right)\right\},\left\{g\left(y_{n}^{*}\right)\right\}$. Now, we prove that

$$
g\left(x_{n}\right)=F(x, y)=g(x) \text { and } g\left(y_{n}\right)=F(y, x)=g(y) .
$$

Since $(x, y)$ is a coupled coincidence point of $F$ and $g$, we have $F(x, y)=g(x)$ and $F(y, x)=$ $g(y)$. Thus $g\left(x_{1}\right)=F\left(x_{0}, y_{0}\right)=F(x, y)=g(x)$ and $g\left(y_{1}\right)=F\left(y_{0}, x_{0}\right)=F(y, x)=g(y)$. Therefore $g\left(x_{1}\right) \preceq g(x), g(x) \preceq g\left(x_{1}\right), g\left(y_{1}\right) \preceq g(y)$ and $g(y) \preceq g\left(y_{1}\right)$. Since $F$ is monotone $g$-nondecreasing on its first argument, $g\left(x_{1}\right) \preceq g(x)$, and $g(x) \preceq g\left(x_{1}\right)$, we have $F\left(x_{1}, y_{1}\right) \preceq F\left(x, y_{1}\right)$ and $F\left(x, y_{1}\right) \preceq F\left(x_{1}, y_{1}\right)$. Therefore,

$$
F\left(x_{1}, y_{1}\right)=F\left(x, y_{1}\right)
$$

Also, since $F$ is monotone $g$-non-increasing on its second argument, $g\left(y_{1}\right) \preceq g(y)$ and $g(y) \preceq g\left(y_{1}\right)$, we have $F(x, y) \preceq F\left(x, y_{1}\right)$ and $F\left(x, y_{1}\right) \preceq F(x, y)$. Therefore,

$$
F(x, y)=F\left(x, y_{1}\right)
$$

From (13) and (14), we have

$$
g\left(x_{2}\right)=F\left(x_{1}, y_{1}\right)=F(x, y)=g(x) \text {. }
$$

Similarly, we may show that

$$
g\left(y_{2}\right)=F\left(y_{1}, x_{1}\right)=F(y, x)=g(y) .
$$

Note that $g\left(x_{2}\right) \preceq g(x), g(x) \preceq g\left(x_{2}\right), g\left(y_{2}\right) \preceq g(y)$ and $g(y) \preceq g\left(y_{2}\right)$. Since $F$ is monotone $g$-non-decreasing on its first argument, $g\left(x_{2}\right) \preceq g(x)$, and $g(x) \preceq g\left(x_{2}\right)$, we have $F\left(x_{2}, y_{2}\right) \preceq$ $F\left(x, y_{2}\right)$ and $F\left(x, y_{2}\right) \preceq F\left(x_{2}, y_{2}\right)$. Therefore,

$$
F\left(x_{2}, y_{2}\right)=F\left(x, y_{2}\right)
$$

Also, since $F$ is monotone $g$-non-increasing on its second argument, $g\left(y_{2}\right) \preceq g(y)$ and $g(y) \preceq g\left(y_{2}\right)$, we have $F(x, y) \preceq F\left(x, y_{2}\right)$ and $F\left(x, y_{2}\right) \preceq F(x, y)$. Therefore,

$$
F(x, y)=F\left(x, y_{2}\right)
$$

From (15) and (16), we have

$$
g\left(x_{3}\right)=F\left(x_{2}, y_{2}\right)=F(x, y)=g(x) \text {. }
$$


Similarly, we may show that

$$
g\left(y_{3}\right)=F\left(y_{2}, x_{2}\right)=F(y, x)=g(y) .
$$

Continuing in the same way, we have that

$$
g\left(x_{n}\right)=F(x, y)=g(x) \quad \text { and } \quad g\left(y_{n}\right)=F(y, x)=g(y)
$$

hold for all $n \in \mathbb{N}$. Similarly, we can show that

$$
g\left(x_{n}^{*}\right)=F\left(x^{*}, y^{*}\right)=g\left(x^{*}\right) \quad \text { and } \quad g\left(y_{n}^{*}\right)=F\left(y^{*}, x^{*}\right)=g\left(y^{*}\right) \quad \forall n \in \mathbb{N}
$$

hold for all $n \in \mathbb{N}$. Since

$$
(F(x, y), F(y, x))=\left(g\left(x_{1}\right), g\left(y_{1}\right)\right)=(g(x), g(y))
$$

and

$$
(F(u, v), F(v, u))=\left(g\left(u_{1}\right), g\left(v_{1}\right)\right)
$$

are comparable, $g(x) \preceq g\left(u_{1}\right)$ and $g(y) \succeq g\left(v_{1}\right)$. Since $F$ has the mixed $g$-monotone property of $X$, we have $g(x) \preceq g\left(u_{n}\right)$ and $g(y) \succeq g\left(v_{n}\right)$ for all $n \in \mathbb{N}$. Also, since $\left(g\left(x^{*}\right), g\left(y^{*}\right)\right)$ and $(F(u, v), F(v, u))=\left(g\left(u_{1}\right), g\left(v_{1}\right)\right)$ are comparable, and $F$ has the $g$-monotone property, then we can show that for $n \in \mathbb{N}$, we have that $\left(g\left(x^{*}\right), g\left(y^{*}\right)\right)$ and $\left(g\left(u_{n}\right), g\left(v_{n}\right)\right)$ are comparable. Now, if $(g(x), g(y))=\left(g\left(u_{k}\right), g\left(v_{k}\right)\right)$ for some $k \in \mathbb{N}$ or $\left(g\left(x^{*}\right), g\left(y^{*}\right)\right)=\left(g\left(u_{k}\right), g\left(v_{k}\right)\right)$ for some $k \in \mathbb{N}$, then $(g(x), g(y))$ and $\left(g\left(x^{*}\right), g\left(y^{*}\right)\right)$ are comparable, say $g(x) \preceq g\left(x^{*}\right)$ and $g(y) \succeq g\left(y^{*}\right)$. Thus from (5) we have

$$
\begin{aligned}
& d\left(g(x), g\left(x^{*}\right)\right) \\
& \quad=d\left(F(x, y), F\left(x^{*}, y^{*}\right)\right) \\
& \quad \leq \alpha \max \left\{d\left(g(x), g\left(x^{*}\right)\right), d\left(g(y), g\left(y^{*}\right)\right), d(F(x, y), g(x)), d\left(F\left(x^{*}, y^{*}\right), g\left(x^{*}\right)\right)\right\} \\
& \quad=\alpha \max \left\{d\left(g(x), g\left(x^{*}\right)\right), d\left(g(y), g\left(y^{*}\right)\right)\right\}
\end{aligned}
$$

and

$$
\begin{aligned}
& d\left(g\left(y^{*}\right), g(y)\right) \\
& \quad=d\left(F\left(y^{*}, x^{*}\right), F(y, x)\right) \\
& \quad \leq \alpha \max \left\{d\left(g(y), g\left(y^{*}\right)\right), d\left(g(x), g\left(x^{*}\right)\right), d\left(F\left(y^{*}, x^{*}\right), g\left(y^{*}\right)\right), d(F(y, x), g(y))\right\} \\
& \quad=\alpha \max \left\{d\left(g(y), g\left(y^{*}\right)\right), d(g(x), g(y))\right\} .
\end{aligned}
$$

From (17) and (18), we have

$$
\max \left\{d\left(g(x), g\left(x^{*}\right)\right), d\left(g(y), g\left(y^{*}\right)\right)\right\} \leq \alpha \max \left\{d\left(g(y), g\left(y^{*}\right)\right), d(g(x), g(y))\right\} .
$$


Since $\alpha<1$, we have $d\left(g(x), g\left(x^{*}\right)\right)=0$ and $d\left(g(y), g\left(y^{*}\right)\right)=0$. Therefore (12) is satisfied. Now, suppose that $(g(x), g(y)) \neq\left(g\left(u_{n}\right), g\left(v_{n}\right)\right)$ for all $n \in \mathbb{N}$ and $\left(g\left(x^{*}\right), g\left(y^{*}\right)\right) \neq\left(g\left(u_{n}\right), g\left(v_{n}\right)\right)$ for all $n \in \mathbb{N}$. Let $n \in \mathbb{N}$. Since $g(x) \preceq g\left(u_{n}\right)$ and $g(y) \succeq g\left(v_{n}\right)$, then from (5) we have

$$
\begin{aligned}
& d\left(g(x), g\left(u_{n+1}\right)\right) \\
& \quad=d\left(F(x, y), F\left(u_{n}, v_{n}\right)\right) \\
& \quad \leq \alpha \max \left\{d\left(g(x), g\left(u_{n}\right)\right), d\left(g(y), g\left(v_{n}\right)\right), d(F(x, y), g(x)), d\left(F\left(u_{n}, v_{n}\right), g\left(u_{n}\right)\right)\right\} \\
& \quad=\alpha \max \left\{d\left(g(x), g\left(u_{n}\right)\right), d\left(g(y), g\left(v_{n}\right)\right), d\left(g\left(u_{n+1}\right), g\left(u_{n}\right)\right)\right\} \\
& \quad \leq \alpha \max \left\{d\left(g(x), g\left(u_{n}\right)\right), d\left(g(y), g\left(v_{n}\right)\right), d\left(g\left(u_{n+1}\right), g(x)\right)+d\left(g(x), g\left(u_{n}\right)\right)\right\} \\
& \quad \leq \alpha \max \left\{d\left(g(x), g\left(u_{n}\right)\right), d\left(g(y), g\left(v_{n}\right)\right), 2 d\left(g\left(u_{n+1}\right), g(x)\right), 2 d\left(g(x), g\left(u_{n}\right)\right)\right\} \\
& \quad=\alpha \max \left\{2 d\left(g(x), g\left(u_{n}\right)\right), d\left(g(y), g\left(v_{n}\right)\right), 2 d\left(g\left(u_{n+1}\right), g(x)\right)\right\} .
\end{aligned}
$$

If

$$
\max \left\{2 d\left(g(x), g\left(u_{n}\right)\right), d\left(g(y), g\left(v_{n}\right)\right), 2 d\left(g\left(u_{n+1}\right), g(x)\right)\right\}=2 d\left(g\left(u_{n+1}\right), g(x)\right)
$$

then $d\left(g\left(u_{n+1}\right), g(x)\right) \leq 2 \alpha d\left(g\left(u_{n+1}\right), g(x)\right)$. Since $2 \alpha<1$, we have $d\left(g\left(u_{n+1}\right), g(x)\right)=0$. Therefore $d\left(g(x), g\left(u_{n}\right)\right)=0$ and $d\left(g(y), g\left(v_{n}\right)\right)=0$ and hence $(g(x), g(y))=\left(g\left(u_{n}\right), g\left(v_{n}\right)\right)$, a contradiction. Thus

$$
\begin{aligned}
d\left(g(x), g\left(u_{n+1}\right)\right) & \leq \alpha \max \left\{2 d\left(g(x), g\left(u_{n}\right)\right), d\left(g(y), g\left(v_{n}\right)\right)\right\} \\
& \leq 2 \alpha \max \left\{d\left(g(x), g\left(u_{n}\right)\right), d\left(g(y), g\left(v_{n}\right)\right)\right\} .
\end{aligned}
$$

Similarly, we may show that

$$
d\left(g\left(v_{n+1}\right), g(y)\right) \leq 2 \alpha \max \left\{d\left(g(x), g\left(u_{n}\right)\right), d\left(g(y), g\left(v_{n}\right)\right)\right\} .
$$

From (19) and (20), we have

$$
\begin{aligned}
& \max \left\{d\left(g(x), g\left(u_{n+1}\right)\right), d\left(g\left(v_{n+1}\right), g(y)\right)\right\} \\
& \quad \leq 2 \alpha \max \left\{d\left(g\left(v_{n}\right), g(y)\right), d\left(g\left(u_{n}\right), g(x)\right), d\left(g\left(u_{n+1}\right)\right\} .\right.
\end{aligned}
$$

By repeating (21) $n$-times, we have

$$
\begin{aligned}
& \max \left\{d\left(g(x), g\left(u_{n+1}\right)\right), d\left(g\left(v_{n+1}\right), g(y)\right)\right\} \\
& \quad \leq 2 \alpha \max \left\{d\left(g\left(v_{n}\right), g(y)\right), d\left(g\left(u_{n}\right), g(x)\right)\right\} \\
& \quad \vdots \\
& \quad \leq(2 \alpha)^{n+1} \max \left\{d\left(g(x), g\left(u_{0}\right)\right), d\left(g\left(v_{0}\right), g(y)\right)\right\} .
\end{aligned}
$$

Letting $n \rightarrow+\infty$ in the above inequalities, we get that

$$
\lim _{n \rightarrow} \max \left\{d\left(g(x), g\left(u_{n+1}\right)\right), d\left(g\left(v_{n+1}\right), g(y)\right)\right\}=0 .
$$


Hence

$$
\lim _{n \rightarrow \infty} d\left(g(x), g\left(u_{n+1}\right)\right)=0
$$

and

$$
\lim _{n \rightarrow \infty} d\left(g(y), g\left(v_{n+1}\right)\right)=0
$$

Similarly, we may show that

$$
\lim _{n \rightarrow \infty} d\left(g(x), g\left(u_{n+1}\right)\right)=0
$$

and

$$
\lim _{n \rightarrow \infty} d\left(g(y), g\left(v_{n+1}\right)\right)=0
$$

By the triangle inequality, (22), (23), (24) and (25),

$$
\begin{aligned}
& d\left(g(x), g\left(x^{*}\right)\right) \leq d\left(g(x), g\left(u_{n+1}\right)\right)+d\left(g\left(x^{*}\right), g\left(u_{n+1}\right)\right) \rightarrow 0 \quad \text { as } n \rightarrow \infty \\
& d\left(g(y), g\left(y^{*}\right)\right) \leq d\left(g(y), g\left(v_{n+1}\right)\right)+d\left(g\left(y^{*}\right), g\left(v_{n+1}\right)\right) \rightarrow 0 \quad \text { as } n \rightarrow \infty
\end{aligned}
$$

we have $g(x)=g\left(x^{*}\right)$ and $g(y)=g\left(y^{*}\right)$. Thus we have (12). This implies that $(g(x), g(y))=$ $\left(g\left(x^{*}\right), g\left(y^{*}\right)\right)$.

Since $g(x)=F(x, y)$ and $g(y)=F(y, x)$, by commutativity of $F$ and $g$, we have

$$
g(g(x))=g(F(x, y))=F(g(x), g(y)) \quad \text { and } \quad g(g(y))=g(F(y, x))=F(g(y), g(x)) .
$$

Denote $g(x)=z, g(y)=w$. Then from (26)

$$
g(z)=F(z, w) \text { and } \quad g(w)=F(w, z) .
$$

Thus $(z, w)$ is a coupled coincidence point. Then from (26) with $x^{*}=z$ and $y^{*}=w$ it follows $g(z)=g(x)$ and $g(w)=g(y)$, that is,

$$
g(z)=z \quad \text { and } \quad g(w)=w .
$$

From (27) and (28),

$$
z=g(z)=F(z, w) \text { and } \quad w=g(w)=F(w, z) .
$$

Therefore, $(z, w)$ is a coupled common fixed point of $F$ and $g$. To prove the uniqueness, assume that $(p, q)$ is another coupled common fixed point. Then by $(26)$ we have $p=g(p)=$ $g(z)=z$ and $q=g(q)=g(w)=w$.

Corollary 2.2 In addition to the hypotheses of Corollary 2.1, suppose that $L=0, \alpha<\frac{1}{2}$, and for every $(x, y),\left(y^{*}, x^{*}\right) \in X \times X$, there exists $(u, v) \in X \times X$ such that $u \preceq F(u, v), v \succeq F(v, u)$, 
and $(F(u, v), F(v, u))$ is comparable to $(F(x, y), F(y, x))$ and $\left(F\left(x^{*}, y^{*}\right), F\left(y^{*}, x^{*}\right)\right)$. Then $F$ has a unique coupled fixed point, that is, there exist a unique $(x, y) \in X \times X$ such that

$$
x=F(x, y) \text { and } y=F(y, x) \text {. }
$$

Proof Follows from Theorem 2.3 by taking $g=I$, the identity mapping.

Theorem 2.4 In addition to the hypotheses of Theorem 2.1, if gx $x_{0}$ and gy are comparable and $L=0$, then $F$ and $g$ have a coupled coincidence point $(x, y)$ such that $g x=F(x, y)=$ $F(y, x)=g y$.

Proof Follow the proof of Theorem 2.1 step by step until constructing two sequences $\left\{x_{n}\right\}$ and $\left\{y_{n}\right\}$ in $X$ such that $g x_{n} \rightarrow g x$ and $g y_{n} \rightarrow g y$, where $(x, y)$ is a coincidence point of $F$ and $g$. Suppose $g x_{0} \preceq g y_{0}$, then it is an easy matter to show that

$$
g x_{n} \preceq g y_{n} \text { and } \forall n \in \mathbb{N} \cup\{0\} \text {. }
$$

Thus, by (5) we have

$$
\begin{aligned}
& d\left(g x_{n}, g y_{n}\right) \\
& \quad=d\left(F\left(x_{n-1}, y_{n-1}\right), F\left(y_{n-1}, x_{n-1}\right)\right) \\
& \quad \leq \alpha \max \left\{d\left(g\left(x_{n-1}\right), g\left(y_{n-1}\right), d\left(F\left(x_{n-1}, y_{n-1}\right), g\left(x_{n-1}\right)\right), d\left(F\left(y_{n-1}, x_{n-1}\right), g\left(y_{n-1}\right)\right)\right\}\right. \\
& \quad=\alpha \max \left\{d\left(g\left(x_{n-1}\right), g\left(y_{n-1}\right)\right), d\left(g\left(x_{n}\right), g\left(x_{n-1}\right)\right), d\left(g\left(y_{n}\right), g\left(y_{n-1}\right)\right)\right\} .
\end{aligned}
$$

On taking the limit as $n \rightarrow+\infty$, we get $d(g x, g y)=0$. Hence

$$
F(x, y)=g x=g y=F(y, x) .
$$

A similar argument can be used if $g y_{0} \preceq g x_{0}$.

Corollary 2.3 In addition to the hypotheses of Corollary 2.1, if $x_{0}$ and $y_{0}$ are comparable and $L=0$, then $F$ has a coupled fixed point of the form $(x, x)$.

Proof Follows from Theorem 2.4 by taking $g=I$, the identity mapping.

Now, we introduce the following example to support our results.

Example 2.1 Let $X=[0,1]$. Then $(X, \leq)$ is a partially ordered set with the natural ordering of real numbers. Define the metric $d$ on $X$ by

$$
d(x, y)= \begin{cases}\max \{x, y\} & \text { if } x \neq y \\ 0 & \text { if } x=y\end{cases}
$$

Define $g: X \rightarrow X$ by $g(x)=x^{2}$ and $F: X \times X \rightarrow X$ by

$$
F(x, y)= \begin{cases}\frac{3\left(x^{2}-y^{2}\right)}{4}, & x>y \\ 0, & x \leq y .\end{cases}
$$


Then

(1) $g(X)$ is a complete subset of $X$.

(2) $F(X \times X) \subseteq g(X)$

(3) $X$ satisfies (i) and (ii) of Theorem 2.1.

(4) $F$ has the mixed $g$-monotone property.

(5) For any $L \in[0,+\infty), F$ and $g$ satisfy that

$$
\begin{aligned}
& d(F(x, y), F(u, v)) \\
& \leq \frac{3}{4} \max \{d(g(x), g(u)), d(g(y), g(v)), d(F(x, y), g(x)), d(F(u, v), g(u))\} \\
& \quad+L \min \{d(F(x, y), g(u)), d(F(u, v), g(x))\}
\end{aligned}
$$

for all $g(x) \leq g(u)$ and $g(y) \geq g(v)$ holds for all $x, y, u, v \in X$ with $g(x) \leq g(u)$ and $g(y) \geq g(v)$.

Thus, by Theorem 2.1, $F$ has a coupled fixed point. Moreover, $(0,0)$ is a coupled coincidence point of $F$.

Proof The proof of (1)-(4) is clear. We divide the proof of (5) into the following cases.

Case 1: If $g(x) \leq g(y)$ and $g(u) \leq g(v)$, then $x \leq y$ and $u \leq v$. Hence

$$
\begin{aligned}
d(F(x, y), F(u, v))= & d(0,0)=0 \\
\leq & \frac{3}{4} \max \{d(g(x), g(u)), d(g(y), g(v)), d(F(x, y), g(x)), d(F(u, v), g(u))\} \\
& +L \min \{d(F(x, y), g(u)), d(F(u, v), g(x))\} .
\end{aligned}
$$

Case 2: If $g(x) \leq g(y)$ and $g(u)>g(v)$, then $x \leq y$ and $u>v$. Hence

$$
\begin{aligned}
d(F(x, y), F(u, v))= & d\left(0, \frac{3\left(u^{2}-v^{2}\right)}{4}\right) \\
= & \frac{3}{4}\left(u^{2}-v^{2}\right) \\
\leq & \frac{3}{4} u^{2} \\
= & \frac{3}{4} \max \left\{\frac{3}{4}\left(u^{2}-v^{2}\right), u^{2}\right\} \\
= & \frac{3}{4} \max \{F(u, v), g(u)\} \\
= & \frac{3}{4} d(F(u, v), g(u)) \\
\leq & \frac{3}{4} \max \{d(g(x), g(u)), d(g(y), g(v)), d(F(x, y), g(x)), d(F(u, v), g(u))\} \\
& +L \min \{d(F(x, y), g(u)), d(F(u, v), g(x))\} .
\end{aligned}
$$

Case 3: If $g(x)>g(y)$ and $g(u) \leq g(v)$, then $x>y$ and $u \leq v$. Hence $v \leq y<x \leq u \leq v$. Therefore $v<v$, which is impossible.

Case 4: If $g(x)>g(y)$ and $g(u)>g(v)$, then $x>y$ and $u>v$. Thus $v \leq y<x \leq u$. 
Subcase I: $x=u$ and $y=v$. Here, we have

$$
\begin{aligned}
d(F(x, y), F(u, v))= & d(0,0)=0 \\
\leq & \frac{3}{4} \max \{d(g(x), g(u)), d(g(y), g(v)), d(F(x, y), g(x)), d(F(u, v), g(u))\} \\
& +L \min \{d(F(x, y), g(u)), d(F(u, v), g(x))\} .
\end{aligned}
$$

Subcase II: $x \neq u$ or $y \neq v$. Here, we have $u^{2}-v^{2}>x^{2}-y^{2}$. Therefore

$$
\begin{aligned}
d(F(x, y), F(u, v))= & d\left(\frac{3\left(x^{2}-y^{2}\right)}{4}, \frac{3\left(u^{2}-v^{2}\right)}{4}\right) \\
= & \frac{3}{4}\left(u^{2}-v^{2}\right) \\
\leq & \frac{3}{4} u^{2} \\
= & \frac{3}{4} \max \left\{\frac{3}{4}\left(u^{2}-v^{2}\right), u^{2}\right\} \\
= & \frac{3}{4} \max \{F(u, v), g(u)\} \\
= & \frac{3}{4} d(F(u, v), g(u)) \\
\leq & \frac{3}{4} \max \{d(g(x), g(u)), d(g(y), g(v)), d(F(x, y), g(x)), d(F(u, v), g(u))\} \\
& +L \min \{d(F(x, y), g(u)), d(F(u, v), g(x))\} .
\end{aligned}
$$

Note that the mappings F and $g$ satisfy all the hypotheses of Theorem 2.1 for $\alpha=\frac{3}{4}$ and any $L \geq 0$. Thus $F$ and $g$ have a coupled coincidence point. Here $(0,0)$ is a coupled coincidence point of $F$ and $g$.

\section{Remarks}

(1) Theorem 1.1 is a special case of Corollary 2.1.

(2) Theorem 1.2 is a special case of Corollary 2.1.

(3) Theorem 1.3 is a special case of Theorem 2.1.

(4) Theorem 1.4 is a special case of Theorem 2.2.

Competing interests

The authors declare that they have no competing interests.

Authors' contributions

All authors read and approved the final manuscript.

\section{Author details}

'Department of Mathematics, Hashemite University, P.O. Box 150459, Zarqa, 13115, Jordan. ${ }^{2}$ Department of Mathematics, Iran University of Science and Technology, Tehran, Iran. ${ }^{3}$ Department of Mathematics, Research Institute for Natural Sciences, Hanyang University, Seoul, 133-791, Korea.

\section{Acknowledgements}

The authors would like to thank the editor and the referees for helpful comments. 


\section{References}

1. Banach, S: Sur les opérations dans les ensembles absraites et leurs applications. Fundam. Math. 3, 133-181 (1922)

2. Abdeljawad, T, Karapınar, E, Taş, K: A generalized contraction principle with control functions on partial metric spaces. Comput. Math. Appl. 63, 716-719 (2012)

3. Abdeljawad, T, Karapınar, E, Taş, K: Existence and uniqueness of a common fixed point on partial metric spaces. Appl. Math. Lett. 24, 1900-1904 (2011)

4. Agarwal, RP, El-Gebeily, MA, O’Regan, D: Generalized contractions in partially ordered metric spaces. Appl. Anal. 87, 1-8 (2008)

5. Amini-Harandi, A, Emami, H: A fixed point theorem for contraction type maps in partially ordered metric spaces and application to ordinary differential equations. Nonlinear Anal. 72(5), 2238-2242 (2010)

6. Je Cho, Y, Saadati, R, Wang, S: Common fixed point theorems on generalized distance in ordered cone metric spaces. Comput. Math. Appl. 61, 1254-1260 (2011)

7. Drici, Z, McRae, FA, Vasundhara Devi, J: Fixed point theorems in partially ordered metric spaces for operators with PPF dependence. Nonlinear Anal. 67(2), 641-647 (2007)

8. Ćirić, LB, Cakić, N, Rajović, M, Ume, JS: Monotone generalized nonlinear contractions in partially ordered metric spaces. Fixed Point Theory Appl. 2008, Article ID 131294 (2008)

9. Nieto, JJ, Lopez, RR: Contractive mapping theorems in partially ordered sets and applications to ordinary differential equations. Order 22, 223-239 (2005)

10. Nieto, JJ, Lopez, RR: Existence and uniqueness of fixed point in partially ordered sets and applications to ordinary differential equations. Acta Math. Sin. Engl. Ser. 23(12), 2205-2212 (2007)

11. O'regan, D, Petrutel, A: Fixed point theorems for generalized contractions in ordered metric spaces. J. Math. Anal. Appl. 341(2), 1241-1252 (2008)

12. Ran, ACM, Reurings, MCB: A fixed point theorem in partially ordered sets and some applications to matrix equations. Proc. Am. Math. Soc. 132(5), 1435-1443 (2004)

13. Karapınar, E, Erhan, I: Fixed point theorems for operators on partial metric spaces. Appl. Math. Lett. 24, 1894-1899 (2011)

14. Shatanawi, W, Samet, B: On $(\psi, \phi)$-weakly contractive condition in partially ordered metric spaces. Comput. Math Appl. (2011). doi:10.1016/j.camwa.2011.08.033

15. Shatanawi, W: Fixed point theorems for nonlinear weakly C-contractive mappings in metric spaces. Math. Comput. Model. (2011). doi:10.1016/j.mcm.2011.06.069

16. $\mathrm{Wu}, \mathrm{Y}$ : New fixed point theorems and applications of mixed monotone operator. J. Math. Anal. Appl. 341(2), 883-893 (2008)

17. $\mathrm{Wu}, \mathrm{Y}, \mathrm{Liang}, \mathrm{Z}$ : Existence and uniqueness of fixed points for mixed monotone operators with applications. Nonlinear Anal. 65(10), 1913-1924 (2006)

18. Bhaskar, TG, Lakshmikantham, V: Fixed point theorems in partially ordered metric spaces and applications. Nonlinear Anal. 65, 1379-1393 (2006)

19. Aydi, H, Damjanović, B, Samet, B, Shatanawi, W: Coupled fixed point theorems for nonlinear contractions in partially ordered G-metric spaces. Math. Comput. Model. (2011). doi:10.1016/j.mcm.2011.05.059

20. Lakshmikanthama, V, Ćirić, LB: Coupled fixed point theorems for nonlinear contractions in partially ordered metric spaces. Nonlinear Anal. 70, 4341-4349 (2009)

21. Karapınar, E: Coupled fixed point theorems for nonlinear contractions in cone metric spaces. Comput. Math. Appl. 59(12), 3656-3668 (2010)

22. Nashine, HK, Shatanawi, W: Coupled common fixed point theorems for pair of commuting mappings in partially ordered complete metric spaces. Comput. Math. Appl. (2011). doi:10.1016/j.camwa.2011.06.042

23. Samet, B: Coupled fixed point theorems for a generalized Meir-Keeler contraction in partially ordered metric spaces. Nonlinear Anal. 72, 4508-4517 (2010)

24. Shatanawi, W: Some common coupled fixed point results in cone metric spaces. Int. J. Math. Anal. 4, 2381-2388 (2010)

25. Shatanawi, W: Partially ordered cone metric spaces and coupled fixed point results. Comput. Math. Appl. 60 , 2508-2515 (2010)

26. Sintunavarat, W, Cho, YJ, Kumam, P: Common fixed point theorems for c-distance in ordered cone metric spaces. Comput. Math. Appl. 62(4), 1969-1978 (2011)

27. Berinde, V: Some remarks on a fixed point theorem for Ćirić-type almost contractions. Carpath. J. Math. 25, 157-162 (2009)

28. Berinde, V: Approximation fixed points of weak contractions using the Picard iteration. Nonlinear Anal. Forum 9, 43-53 (2004)

29. Berinde, V: On the approximation fixed points of weak contractive mappings. Carpath. J. Math. 19, 7-22 (2003)

30. Berinde, V: General contractive fixed point theorems for Ćirić-type almost contraction in metric spaces. Carpath. J. Math. 24, 10-19 (2008)

10.1186/1029-242X-2013-565

Cite this article as: Shatanawi et al.: Almost contractive coupled mapping in ordered complete metric spaces. Journal of Inequalities and Applications 2013, 2013:565 